\title{
Numerical investigation of superheater tube failure
}

\author{
H. H. Al-Kayiem \& T. M. B. Albarody \\ Mechanical Engineering Department, Universiti Teknologi PETRONAS, \\ Perak, Malaysia
}

\begin{abstract}
Industrial superheaters in petrochemical plants possess leakages due to failure in many areas. This paper presents the results of investigations into identifying the failure causes. The investigations were carried out by simulating the heating process of a superheater. The simulation was carried out numerically using ANSYS mechanical commercial software. The simulation results indicated that the superheater tubes were subjected to direct radiation heat transfer as well as flame violence. The leakage spots were formed due to cracks in the material mainly at the joint points between the tubes and the header. It was also realized that the welding at the connection areas of the pipes and the header had weakened the material and formed low thermal resistance spots which could not stand the $510^{\circ} \mathrm{C}$ temperature and consequently, it had either melted or cracked.

Keywords: boiler, superheater, thermal wave, thermal fatigue, thermal stress.
\end{abstract}

\section{Introduction}

The basic failure mechanism, in the piping process, is fatigue due to vibration and/or thermal stresses caused by internal and/or external flows in pipes, junctions, and bends. When high temperature exists in the process, the possibility of thermal fatigue increases the possibilities of piping failure. In the industrial practice, such problem is commonly associated with boilers, risers, and pipes subjected to intermittent internal flow and periodic heat impact from internal or external sources. In particular, the evaporator's risers and superheater piping systems are exposed to high temperature, which in some occasions becomes unsteady and/or non-uniform due to fault functioning of the burners in the furnace, and in the fuel feeding pumps. In conventional and combined-cycle plants, boiler and heat 
recovery steam generator (HRSG) tube failures have been the main availability problem for as long as reliable statistics have been kept for each generating source [1]. The methods of investigating such fatigue problems are mainly based on inspot inspection and analyses. But, even with the high monitoring instrumentations, as in the nuclear power plants, pipe degradation due to thermal fatigue may happen due to turbulent temperature mixing effects that cannot be adequately monitored by common thermocouple instrumentations.

Based on the theories of damage and plasticity, Oller et al. [2] have developed a thermo plastic damage model and thermo-mechanical coupled model using the heat balance equation for the coupled thermo-mechanical that is deduced from the first thermodynamic law and Fourier's conduction equation. The models have been solved by developed finite element code, which has been applied in a notched sample, made of steel, under fatigue effects. Also, they used COMET version 5 to investigate industrial case of an aluminium engine alternator support.

Zhao and Chow [3] have developed a numerical algorithm for a damagecoupled viscoelastic-fatigue material model and applied the algorithm on eutectic material, $\mathrm{Sn}-\mathrm{Pb}$ solder, exhibiting strain-softening behaviour. The numerical algorithm employs a modified explicit method with adaptive sub-stepping based on the local error control for which the stress (constitutive) Jacobian explicit solution is derived. The algorithm is implemented in a commercial finite element code, ABAQUS (Version 6.2) via its user-defined material subroutine. The algorithm is verified with single-element simulations for uniaxial test, tensile creep, and fatigue simulations to attain an optimized algorithm. Then, they extended the application to two and three-dimensional analyses of a miniature specimen under monotonic tensile loading and fatigue loading.

Zhou et al. [4] used ANSYS finite element to predict the thermal fatigue in tundish cover in continuous casting process. The temperature and stress fields have been simulated in the cover, which was discrete to 17676 nodes and 9682 elements. However, they concluded that there was a large temperature gradient within the tundish cover. Also, the cover was subjected to cyclic temperature load. From the results of experimental study and finite element simulation of thermal fatigue failure of the tundish cover device for continuous casting, it could be concluded that the finite element simulation precisely depicted the failure of the tundish cover.

Computational methods using Finite Volume and Finite Element techniques for simulation and analysis are powerful tools in analysing the failure problems in thermofluid systems, as demonstrated by the presented literature. The problem of the flow induced vibration and thermal loadings are a multi-physics phenomenon which required thermo-hydraulic analysis and structural analysis for the evaluation of mode shapes, natural frequency and cyclic loadings, which are the main reasons of piping and tube systems failure. It is clear that most of the previous attempts to study the thermal fatigue are industrial base problems.

The simulations simplified to two-dimensional (2D) model is often used and there is no methods can be totally suitable for the life estimation of structures, particularly practical structures, subjected to accumulated thermal and mechanical 
fatigue damage. The motivation to conduct the present investigation is industrial base, as well.

The objective of the present paper is to present and discuss the results of numerical procedure which has been used to simulate the internal and external hydrothermal processes, and the resulting stresses in a superheater tubes. The aim of the analysis is to make a decision on the reason of the failed superheater in a petrochemical plant. Finite element technique has been used utilizing ANSYS 14. The simulation has been carried out in 2-D and 3-D domains, and the stresses levels have been predicted to capture the spot of failures.

\section{Background and problem identification}

The superheater tubes of D-boiler in the 'Integrated Petrochemical Complex' Pahang - Malaysia possessed a failure which led to large leakage and reduction in the plant productivity. Cracks were occurring at the connection portions between the tubes and the main header of the superheater. To investigate the problem, it was decided to develop a numerical simulation to evaluate and analyse the stresses and to decide the reason of these failures in the steam superheater tubes. Decision was made to model the failed tubes in accordance with the actual geometries as supplied by the client.

The D-boiler is of the horizontal gas path type, which means that the tubes are arranged vertically between top and bottom headers. The D-boiler produces steam on one pressure level, which consists of economizer sections for heating up the feed water, evaporator sections to evaporate the water and superheater sections to superheat the produced steam. The D-boiler is designed for $120 \mathrm{t} / \mathrm{h}$ steam production with 54 bars and $430^{\circ} \mathrm{C}$ steam pressure and temperature, respectively. D-boiler is equipped with four rows of bare tube superheater to limit the heat flux from the duct burner. Four rows of finned superheaters are installed behind the bare tubes. The steam temperature is limited by inter-stage attemperation between the two (finned and bare) superheater sections.

\subsection{Problem formulation}

To create a real simulation environment of the operational conditions in the computer, we found that acquisition of site data was essential to be used as boundary conditions. Accordingly, in-site measurements have been carried out for around three months and the collected data were utilized in the simulation. The acquired data represents the thermal field in front and in the back locations of the superheater, the thermofluid parameters inside the tubes, such as the flow rates, the temperatures, and the steam quality. The failed cases were simulated by ANSYS mechanical software in 2-D and 3-D configurations and the simulation results have been classified and analysed.

The superheater layout configuration, specification, operational conditions, and the material properties that would be used in the present simulation have been summarized as in the following sections: 


\subsection{Superheater design parameter}

The superheater was modelled as a boiler of six headers spanned by $11450 \mathrm{~mm}$. Two are as bottom headers, of $3710 \mathrm{~mm}$ length, and four as top headers, of 4055 $\mathrm{mm}$ (as shown in fig 1).
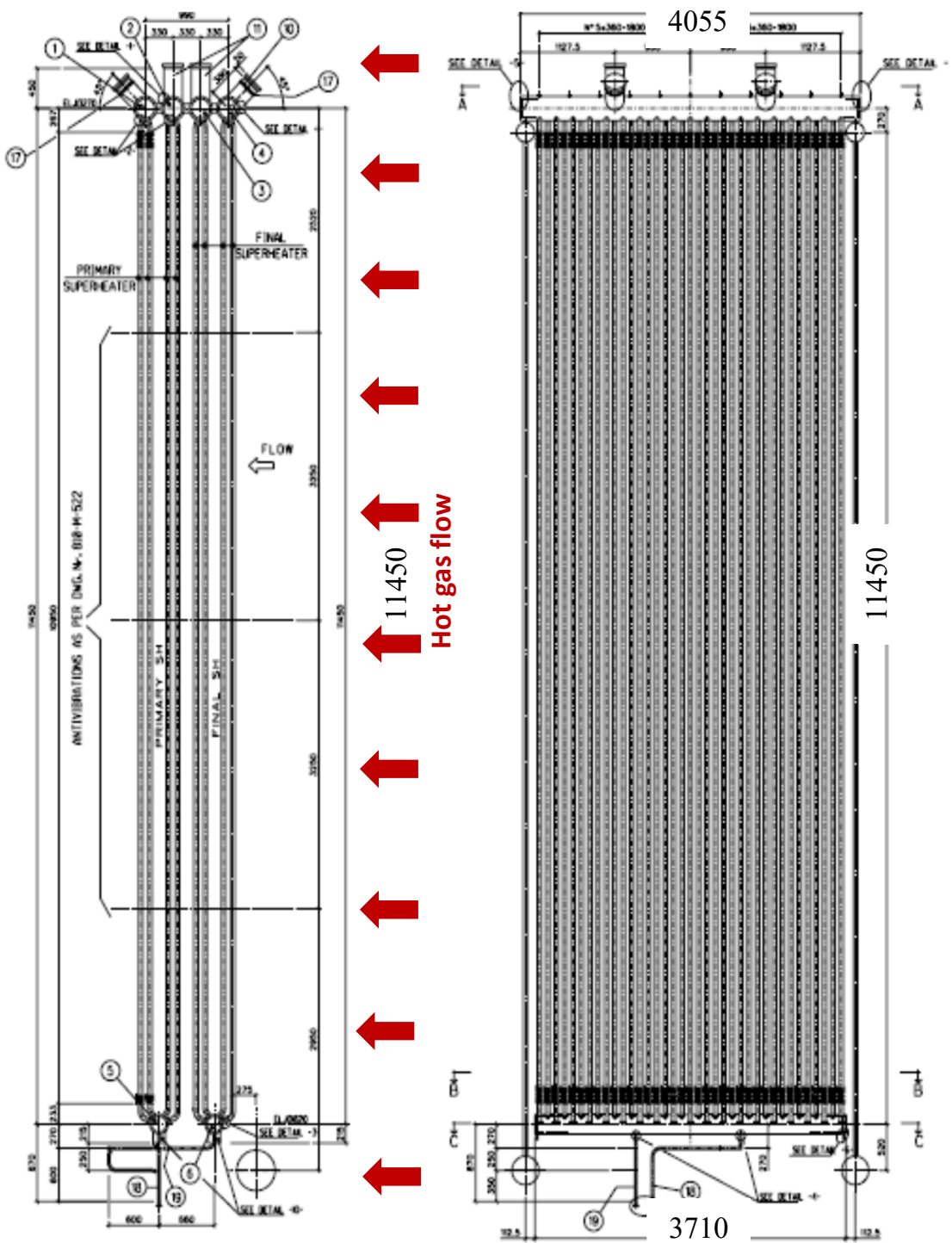

Figure 1: Outlines of the investigated superheater (geometries in $\mathrm{mm}$ ) (modified after (C) Macchi - a division of Sofinter spa). 
The superheater consists of 284 tubes with $50.8 \mathrm{~mm}$ internal diameter. 142 tubes are for primary super-heating and the other 142 tubes are for final superheating process. The tubs are aligned in four levels with ascendant distances between the tubes equal $50.8 \mathrm{~mm}$.

\subsection{Operational conditions}

The average superheater internal pressure is 57.1 bars, while the external gases temperature is $510^{\circ} \mathrm{C}$. The other superheater specification that used as input parameters for the simulation are listed in Table 1.

Table 1: $\quad$ Specification of the boiler as provided in the tender document.

\begin{tabular}{|l|c|c|}
\hline \multirow{2}{*}{ Description } & \multicolumn{2}{|c|}{$\begin{array}{c}\text { Utility boiler } \\
\text { [Boiler-D] }\end{array}$} \\
\hline Pressure (bar) & (design) & 57.1 \\
\cline { 2 - 3 } & (operating) & 54 \\
\hline Type & & Water tubes \\
\hline Number of units & & 1 \\
\hline Boiler operating temperature $\left({ }^{\circ} \mathrm{C}\right)$ & 510 \\
\hline
\end{tabular}

\section{Simulation scheme}

\subsection{Material properties}

The headers of the superheater are made of

- Tube material: A213 T11;

- Headers material: A335 P11;

- Ideal linear-elastic model;

- Temperature dependent properties (E-modulus, expansion coefficient, conductivity, specific heat) have been investigated, in order to feed to the simulation.

\subsection{Model meshing}

Mesh built up in several sections;

- Higher order elements are used throughout the model to increase the accuracy of the solution;

- The default setting of the number of element is the ideal for ANSYS mechanics, for stress analysis [5].

\subsection{Boundary conditions}

The boundary conditions for the thermal model are:

Gas turbine flow, temperature, composition;

Duct burner heat input; 
Steam line terminal point pressure;

Steam temperature attemperation set point.

The steam properties have been monitored and recorded from the CUF in the main control room of the plant. The mean daily values of the HP, EC and the $\mathrm{SiO}_{2}$, in the 6 headers, for three months have been recorded and considered in the investigations. The simulated superheater is shown in fig 2.

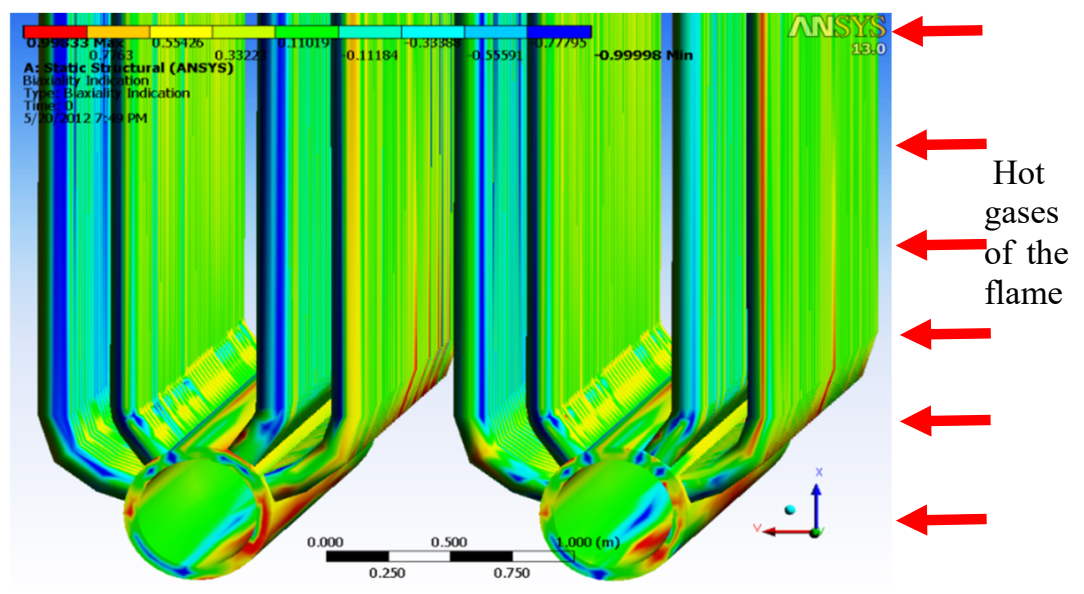

Figure 2: The lower segment of the simulated superheater.

\section{Results and discussion}

The main parameters studied in this FE simulation and analysis, which are effecting the structure of the superheater are: the effect of thermal expansion, the effect of hard fluctuation in the thermal wave, effect of short term overheatingstress rupture, and effect of flame impingement.

\subsection{Effect of thermal expansion}

One of the consequences of the thermal expansion of the superheater components is the non-similar or identical expansion. The general observation of the thermal expansion is the vertical movement of the lower header. The results of the nonsimilar expansion are represented in the small to marginal deformation of the bottom header as can be seen in fig 3 . The figure is 100x enlarged and therefore shows a higher deflection than the actual. 


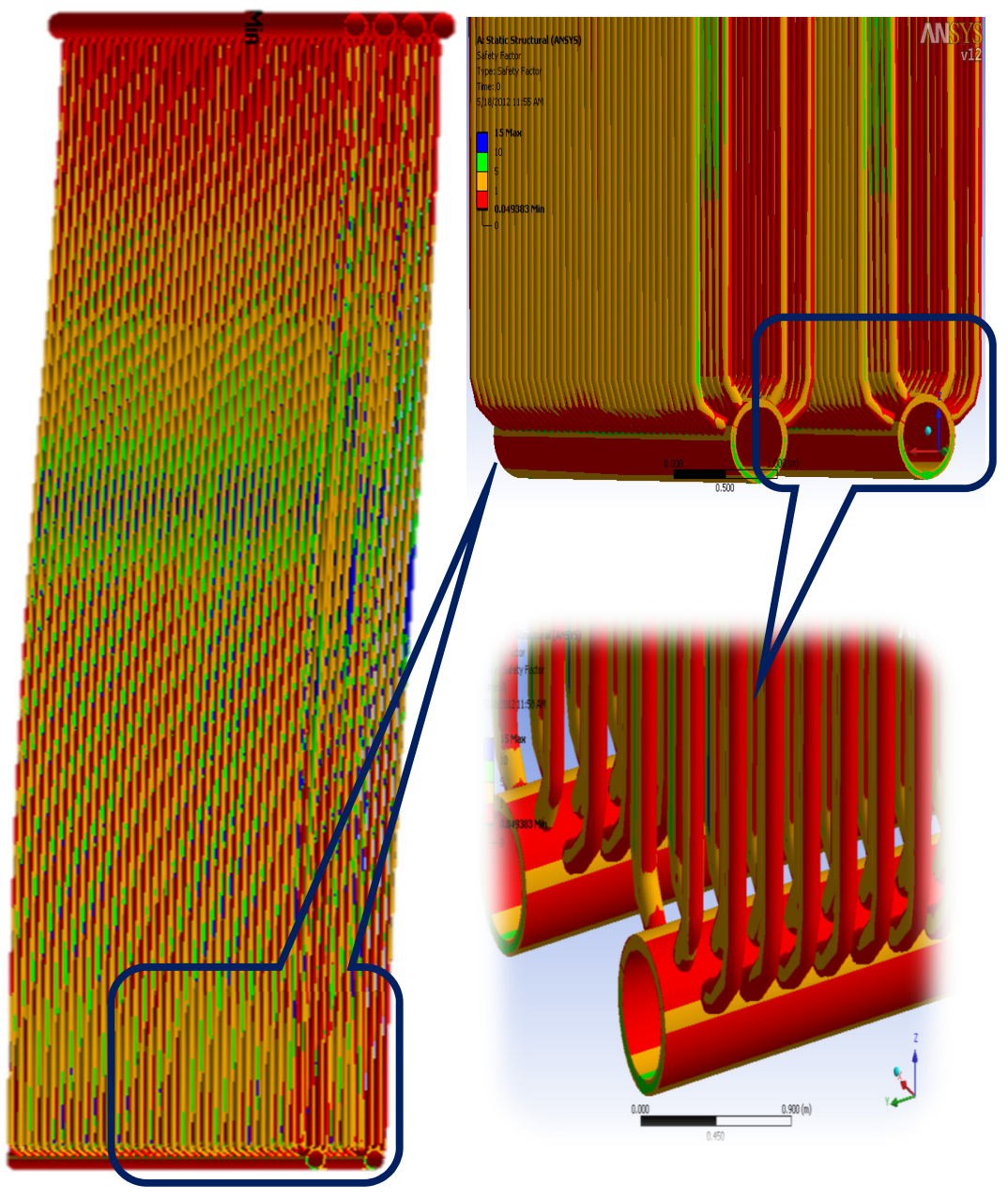

Figure 3: Header deformation due to thermal expansion.

Due to the larger thermal growth of the hotter tubes and the restrictions in their expansion, the weld connections are subject to a compressive stress instead of the usual tensile stress.

\subsection{Effect of fluctuation in thermal wave}

At first, the peak stresses in the most critical superheater module were investigated. The most critical phase is during the start-up of the D-boiler at which 
all components are cold and the thin walled parts will heat up faster than the thick walled components.

In the current simulation, variation in the applied temperature is considered within the actual measured range of $250-510^{\circ} \mathrm{C}$. It has a sinusoidal form similar to the recorded history in the furnace. At such fluctuation in the temperature, it is expected that the thermal fatigue could result in mechanical stresses having cyclic stresses in the material of the tubes and headers.
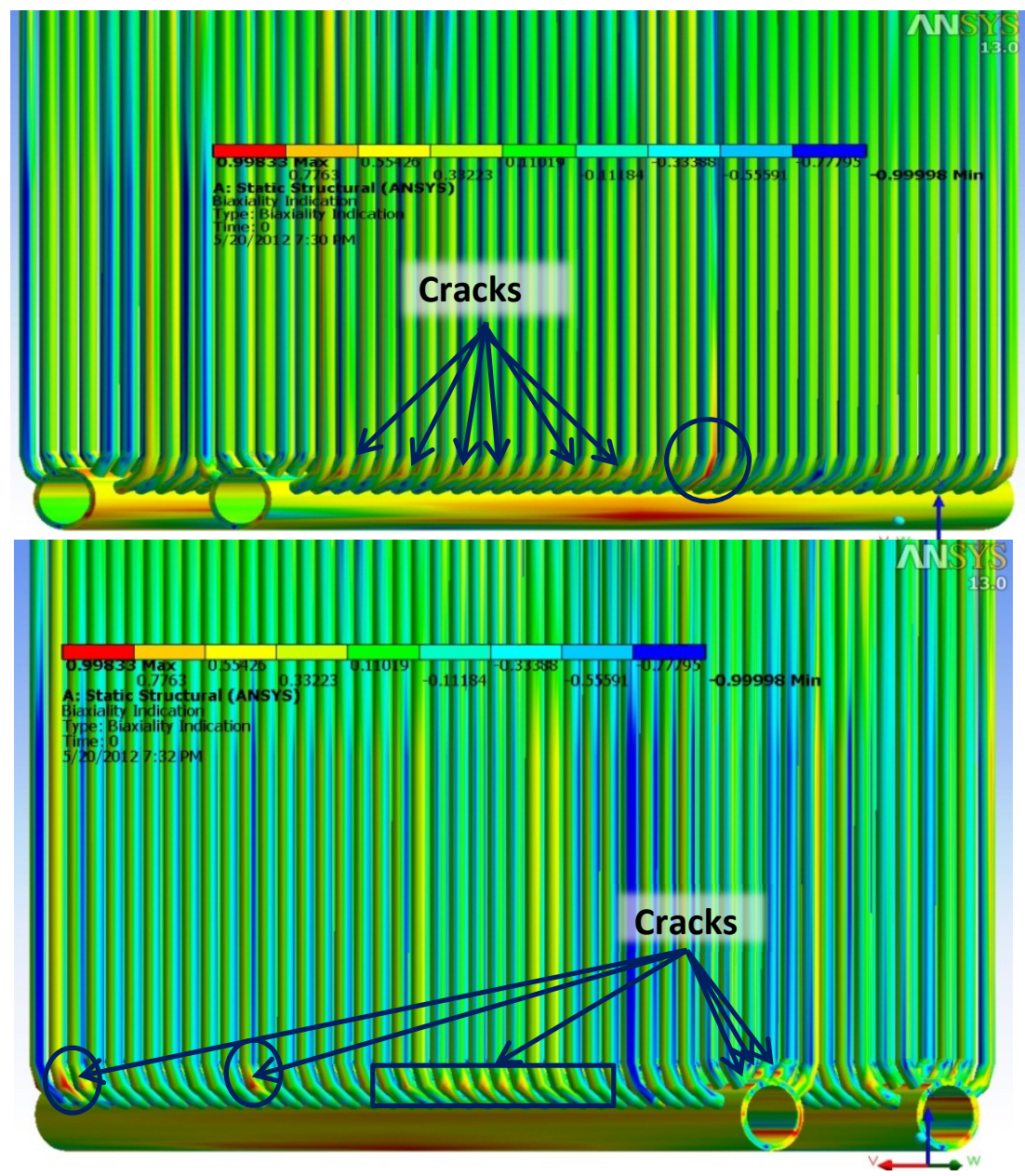

Figure 4: Predicted locations of cracks, mostly in the bend portion of the tubes.

As a result of repeated relative movement, or cyclic differential expansion, under repeated thermal cycling, damages in the form of cracking would occur anywhere in the super heater components. But, of course, the damages will be 
concentrated in the weld connection ports between the tubes and the lower header that supported, and the bending portion of the tubes, as shown in fig. 4 .

\subsection{Effect of short term overheating}

A local overheating above the design temperature is assumed in the current simulation. When the flame travels with high velocity with not completed combusted particles, it may impose direct negative effect on any structure, it identified as flame violence. A permanent deformation could be occurred at relatively low stress levels as a result of localized overheating. This is usually resulted in bulging and eventually failure by stress rupture, or usually due to flame impingement that cause local overheating.

In the current simulation it is observed that the time to failure will increase as internal pressures or loading decrease. However, bulging and distortion can be significant at low stresses, as temperatures increase. It is shown that the damage is typically characterized by localized deformation or bulging on the order of $3 \%$ to $10 \%$ or more, depending on the alloy, temperature and stress level. While, it is found that the deformations disappear when minimizing the localized temperature excursions.

The deflection of the tubes in the Z-direction is calculated at approximately +1 and $-1 \mathrm{~mm}$. The stresses with negative values indicate compression stress in place.

\section{Conclusions}

An industrial superheater has been simulated to investigate the failure in its pipes. In-site recorded operational data have been input to the simulation, as boundary conditions. Analysis of the simulation results have shown that the stresses are having cyclic nature, which in turn, led to fatigue and cracks. Also, the configuration of the superheater design is leading to non-identical elongation in the rows of pipes. The frontal rows are exposed to higher thermal energy and are elongated in the vertical direction more than the pipes in the second rows. This causes rotational deformation in the lower header, and as consequences, cracks in the bending portions of the pipes.

It is recommended to extend the analysis to predicted and compare the stresses in different rows of pipes to suggest a possible solution to reduce the failure of the condenser pipes. Also, further investigations are essential to determine the welding spots between the pipes and the headers, where most of the failures take place.

\section{Acknowledgements}

The simulation results have been carried out under a consultancy contract between Universiti Teknologi PETRONAS (UTP) and the Petrochemical complex in Pahang - Malaysia. The authors are expressing their appreciation to UTP for the logistic and administrative support provided to conduct the research work. 


\section{References}

[1] B. Dooley and W. McNaughton, Boiler Tube Failures: Theory and Practice 3 Volumes, BPRl, CA, 2010.

[2] S. Oller, O. Salomón, and E. Onate, A continuum mechanics model for mechanical fatigue analysis, Mater. Sci. 32 (2005) 175-195.

[3] A.H. Zhao, and C.L. Chow, An efficient explicit algorithm for damagecoupled viscoplastic fatigue model, Finite Elem. Anal. Des. 43 (2007) 681690.

[4] Xia Zhou, Zhanfei Tang and Guohui Qu 2010, Thermal stress and thermal fatigue analysis of the continuous casting tundish cover, Materials Science and Engineering A 527 (2010) 2327-2334, DOI:10.1016/j.msea.2009.11.068.

[5] ANSYS MechanicalTM ${ }^{\mathrm{TM}}$ software manual. 